\title{
So Far, so Similar? Labour Market Feminization in Italy and Chile
}

\author{
Renata Semenza ${ }^{1} \cdot$ Giorgio Boccardo $^{2} \cdot$ Simone Sarti $^{1}$ (D)
}

Accepted: 1 November 2020 / Published online: 20 November 2020

(c) The Author(s) 2020

\begin{abstract}
The article aims to analyse gender segregation in the labour market while comparing two national contexts in Europe and Latin America. Specifically, it will consider the growth trends of female employment in the last 25 years (1992-2017), its distribution between activity sectors and occupations, and the gender pay gap. Feminization models and gender inequalities are framed within labour market segmentation theories, which are in partial contrast to human capital theories and neoclassical economics. The initial hypothesis is that the gender distribution of occupations measured by a segregation index is similar in Italy and Chile, despite significant differences in the socio-economic and institutional contexts. Through this intercontinental comparison, the article intends to shed light on women's labour market conditions and segregation patterns, which are multidimensional and generalizable (transcontinental) phenomena, connected to the unequal division of labour in the new post-industrial order.
\end{abstract}

Keywords Labour market segmentation - Gender segregation · Italy $\cdot$ Chile $\cdot$ Comparative studies $\cdot$ Dissimilarity index

\section{Introduction}

The article, elaborated within the INCASI $^{1}$ project, aims to analyse gender segregation in the labour market by comparing two national contexts in Europe and Latin America.

Let us immediately clarify the justification principles for the comparison between the two countries. Although the two national contexts are very different in geographical, historical, political and cultural factors, the choice to compare Italy and Chile derives essentially

\footnotetext{
1 International Network for Comparative Analysis of Social Inequalities (INCASI), Horizon 2020-Rise programme (Marie Sklodowska-Curie GA No. 691004), coordinated by Pedro López-Roldán. This article reflects the author's view only and the agency is not responsible for any use that may be made of the information it contains.

Simone Sarti

simone.sarti@unimi.it

1 Department of Social and Political Sciences, University of Milan, Dip. Di Scienze Sociali e Politiche, Via Conservatorio, 7, 20122 Milan, Italy

2 Department of Sociology, Faculty of Social Sciences, University of Chile, Santiago, Chile
} 
from two factors. First, Chile's GDP growth was spectacular in the 2000s, leading it to resemble advanced economies, particularly those of Southern Europe, which, on the other hand, experienced stagnation in GDP and a greater impact than the global financial crisis of 2008. Second, Chile has embarked on an incomparable neo-liberal path (Ruiz 2019) with any other Latin American country (e.g. Argentina or Brazil). This suggests that the phenomena of the labour market are typical of a market-oriented economy, such as those of more developed economies, unlike state-led economies such as Argentina.

This does not mean, theoretically, to adopt the perspective of convergence theories, according to which all the societies, as they move from the early industrial development to complete industrialization tend to move towards a condition of similarity in terms of general socio-economic norms and developments. On the contrary, our approach is based rather on the idea that structures — such as the segmentation of the labour market—are partially independent of the institutional path and are instead linked to demand-side reasons, and to sociological and cultural aspects.

The article therefore investigates the degree of variance of women integration models in the labour market, adopted in different social and national environments. It specifically considers the growth trends of the female workforce in the last 25 years, its distribution between activity sectors and occupations, and gender pay gaps. The article therefore aims to contribute, through this transnational comparison, to the study of inequalities declined according to gender, which constitutes one of the transversal variables of the Amosit model, within the European Horizon 2020 INCASI project.

From the theoretical background, feminization models and gender inequalities are framed within labour market segmentation theory, as an alternative to human capital theories and neoclassical economics. Then, the article presents some descriptive data on the labour market in the two countries.

Using the 1992-2017 historical series in both countries, through the same harmonized equivalent labour force survey dataset, the article describes the trajectories of labour market feminization in Italy and Chile and measures gender segregation using a dissimilarity index - the Women and Employment Index (WEI). Hence, empirically, the article has two objectives. One is to make a comparative analysis of the two labour market trends using the standard labour force indicators and following the gender dichotomy. The second, considering the segregation index, is to explain the patterns of labour inequalities and if the effects of gender segregation are similar or different in the two contexts.

\section{Labour Market Segmentation and Gender Segregation: Theoretical Elements}

Labour market segmentation theories have arisen, since the 1970s, as an alternative paradigm to human capital theories and neoclassical economics, which assume that working positions and wages depend mainly on investments in education and productivity levels.

For the orthodox theory, in fact, labour market segmentation mainly depends on the economic system, namely the division among economic activity sectors, and impacts on employment characteristics and the labour market structure. Usually, each occupation represents the frame of relative socio-economic, cultural and welfare resources, such as income, educational attainment and social protection.

In Latin America, this relationship has been highlighted by the "structural heterogeneity" theory-proposed by Pinto (1976) and continued by Salvia and Chavez-Molina 
(2013) — which defines structural differences in labour productivity and between economic sectors. This thesis, which incorporates a number of aspects of the underdevelopment economy, implies the coexistence of sectors, branches or activities whose labour productivity - given the composition of the invested capital — is high and similar to that of developed countries, with others whose productivity (given their backward technological level) is very low or zero.

New heterodox theories were developed from the 1970s to 1980s in opposition to neoclassical economics. The dual labour market theory (Doeringer and Piore 1971) assumes that over time the economic process divided the labour market into two sectors, the primary sector consisting in well-paid and stable jobs, career opportunities, unionization and good working conditions, and the second sector characterized by low-paid and temporary jobs, poor working conditions and few chances of advancement. Through the construction of internal labour markets (ILMs) as an organizational tool, companies perpetuate stability for primary sector workers, in order to face the uncertainty of demand. Hence, wage structure, employment conditions and segmentation do not exclusively derive from individual attributes but also from demand-side drivers, such as employers' attitudes or the broader structure of the economy. A radical version of the dual labour market theory (Edwards, Reich and Gordon 1975) argues, in the Marxist sense, that monopolistic capitalism has led to division both in the industrial sectors (uneven growth across industries) and in the workforce, wages and mobility patterns within the labour market.

In partial contrast to the two previous theories, the Cambridge School of labour market segmentation (Rubery 1978) recognizes that workers play a more active role and consider other complementary aspects to be crucial. In addition to workforce characteristics (such as education, qualifications, age, gender, nationality and so on) linked to different conditions within the labour market, on the demand side, it considers economic and commercial strategies, business ideologies and practices, and in particular labour flexibility and outsourcing. The Cambridge School also highlighted the role of labour institutions and public policies which can indeed compensate inequalities, but can also perpetuate them and reinforce employment divisions.

All these theories assume three recurrent conditions. First, there is not a single labour market but a division of the labour force into two or more segments that structure hierarchical positions corresponding to specific occupational profiles among workers. Second, there is limited mobility between segments. Third, the differences in working conditions cannot only be attributed to differences in productivity. The recent labour market segmentation theories (Grimshaw et al. 2017) argue that differences in the working conditions and status of different groups of workers also depend on socio-economic characteristics: labour supply-side attributes may have an influence on the labour market outcomes.

One of the recurrent inequalities - based on individual attributes-is gender related.

Some important contributions to the topic of occupational segregation alongside the gender dimension, come from the US debate between 1990 and early 2000s. Notably Charles and Grusky (2004) indicating the sexual segregation of work and gender inequalities as structural features of contemporary economies. They have framed modern pattern between two distinct cultural principles. Essentialist presumption (women and men have fundamentally different tastes and are accordingly oriented to different types of occupations) and vertical presumption (men are allocated for prestigious and high-paying positions that require the most substantial human capital investments). A sexual division of labour exists in all cultures, as illustrated by anthropological research (Mead 1949). It is a universal phenomenon, but the assignment of jobs to men and women varies in different cultures. Since the 1960s, historical and sociological research has tried to explain the 
process of social construction of the division of labour and the formation of distinct gender identities. The focus is on the complex interaction of reproduction activities and productive work for the wage economy, as well as on the specificity of women's roles, which are studied in their historical evolution, during the industrialization process and subsequently in their configuration in contemporary society, mainly driven by the service sectors.

Following mainstream neoclassical economics, the principal cause of gender inequality and segregation in the labour market is explained by the human capital theory. It assumes that the position of men and women in work and employment is different because they have different preferences, different dispositions to invest in their human capital, such as education, training and preparation for work in general, and different attitudes towards work itself (Hakim 2000). Recent studies have highlighted other aspects, such as differences in competitiveness and risk-taking (Hoffman and Averett 2016). Hence, the economists possessed a strong interpretative paradigm to explain inequality, even if they were not concerned with clarifying why preferences differ among women, why they can change over time and how they vary depending on the circumstances.

The original risk of those approaches was that they could justify inequality based on individual orientation, as if the preferences were not shaped by social norms or cultural stereotypes.

The human capital model began to show its limits when women reached equal or higher educational levels than men. In all developed countries, raising female education has reduced gender inequalities in activity rates, but clear effects of the gender gap, segregation and discrimination are still evident.

A vast, especially neo-institutionalist literature, created by Colette Fagan, Jill Rubery, Mary Daly, Rosemary Crompton, Florence Jaumotte and others, has shown that more than male participation, female participation is conditioned by national institutions, such as welfare regimes, social policies or employment protection legislation. Both gender studies applied to welfare systems and the Varieties of Capitalism perspective have well illustrated how the sexual division of labour and the existence of more or less egalitarian family models ${ }^{2}$ have historically developed in different national contexts (Crompton 1999).

Women's mass entry onto the labour market since the 1980s has been the most revolutionary change in developed economies, with immense effects on the rise of dual-income families, the demand for services and demographic trends. Female labour supply is influenced-more than that of men-by redistributive policies (via services, reconciliation measures and other incentives), as well as by the characteristics of labour demand and economic sectors, and the organizational environment (managerial culture, socialization models).

Feminist socio-economics on gender inequalities and discrimination has enriched our understanding of the mechanisms and constraints that too often make women a "secondary dual earner" (Grimshaw et al. 2017), even when they have the same skills and the same level of productivity.

The article focuses in particular on gender segregation, which manifests itself in differences in patterns of gender representation within occupations (both classified by industries and professional status) and within different employment status and employment contract groups. "Gender segregation means that women and men to a certain extent work in

\footnotetext{
${ }^{2}$ As an example, in some European countries, where there has been a shift from a traditional to an egalitarian family model, the diffusion of egalitarian norms combined with high levels of education are the preconditions for higher fertility rates (Esping-Andersen and Billari 2015).
} 
different occupations or in different sectors or under different contractual terms and conditions" (Emerek et al. 2003).

\section{Trajectories of Labour Market Feminization in Europe and Latin America}

In almost all the European Member States, despite increasing in the last decades, employment and participation rates for women are still systematically lower than for men, while unemployment and, especially, inactivity rates are higher, particularly in the case of women with care responsibilities.

The gender gap remains significant. In southern Europe, part-time work is largely involuntary and often associated with short hours and marginal, low-paid jobs, which are particularly common among low-skilled women. Part-time work is also one of the key factors contributing to the existing gender pay gap, as these jobs tend to be associated with lower hourly pay, fewer career opportunities and less social protection, such as unemployment benefits or pension, compared to full-time jobs. Employed women also show a higher incidence in temporary jobs and in lower pay sectors and occupations than men. In spite of more than thirty years of equal pay legislation, the gender pay gap ${ }^{3}$ has persisted across all Member States regardless of the overall level of female employment (Vosko et al. 2009). According to Eurostat, in 2017, women's gross hourly earnings were on average $16.0 \%$ below those of men in the EU28, with wide differences between the countries. ${ }^{4} \mathrm{~A}$ part of the pay gap is related to the differences in the average characteristics of working men and women such as: age, education, occupation, economic activity, employment contract, work hours, job experience, firm size, or employment in the private versus the public sector. Recent estimations have shown that these factors explain a small part of the gender pay gap. Eurostat estimates (based on the 2014 Structure of Earnings Survey microdata) show that, at the EU level, only $31 \%$ of the difference between men and women's hourly earnings can be attributed to the difference in the observed personal and job characteristics mentioned above, which are on average less favourable for women compared to men. The remaining two thirds are likely to be caused by career breaks following childbirth and discrimination in hiring, career progression and labour market opportunities (OECD 2019; Boll, Rossen and Wolf 2017).

In Latin America, it is the structural heterogeneity of the labour market that has historically reproduced gender inequalities. A recent study confirmed that there are still high levels of occupational gender segregation, which affects the opportunities for wage employment, full-time jobs or temporary contracts, social security or greater degrees of economic autonomy (Espino and De los Santos 2019). ${ }^{5}$ Furthermore, there are different labour trajectories for women, which reproduces gender inequalities. On the one hand, female professionals and technicians with high to middle incomes have difficulties achieving economic

\footnotetext{
3 According to the definition used by the European Commission, the gender pay gap is the difference between the average gross hourly earnings of male and female paid employees as a percentage of the average gross hourly earnings of male paid employees.

${ }^{4}$ Retrieved 7 February 2020, from the Eurostat Interact website: https://ec.europa.eu/eurostat/statistics -explained/index.php/Gender_pay_gap_statistics.

5 The research was conducted in Brazil, Colombia, Costa Rica, Ecuador, El Salvador, Guatemala, Mexico and Uruguay.
} 
autonomy or managerial positions. On the other hand, women with low educational levels are employed in domestic services, low-skilled jobs (retail and traditional service activities) or the rural sector, in addition to having a greater burden of unpaid care work and higher rates of early maternity. According to the Economic Commission for Latin America and the Caribbean (CEPALSTAT), in Latin America in 2017 77.6\% of women worked in low productivity activities (such as service, retail and agriculture), while the percentage of men was only $55.2 \%,{ }^{6}$ confirming that both high- to medium- and low-skilled women are employed in "female occupations" (De Oliveira and Ariza 1999).

If we consider the condition of women in society in a more general sense, there are significant differences between the two countries. According to the Women, Business and the Law Index (WBL 2019 score), Italy is in 22nd place with a score of 94.38 out of 100, while Chile is in 97th place with a score of 77.50, which is nevertheless still higher than the global average of 74.71. However, on narrowing the field to analyse the labour market and segregation models, we found many similarities that justified the comparison in methodological terms.

Firstly, in the context of Latin America, Chile has experienced an accelerated process of labour market feminization, more similar to the southern European countries than to the rest of Latin America. Italy and Chile show similar trends both in women's participation rates (57.8\% in Chile, 55.6\% in Italy) and employment rates (52\% in Chile, $48.2 \%$ in Italy), according to the OECD (2019). The gender wage gap was $12.5 \%$ in Chile and $5.6 \%$ in Italy $^{7}$ and part-time work ${ }^{8}$ is more concentrated among women $(24.9 \%$ and $32.4 \%$ respectively) than men (12.5\% and $8.3 \%$ respectively). ${ }^{9}$

Secondly, despite having a different economic production structure, the feminization rates by sector of activity are similar. According to the World Bank, in 2017 female employment in the services sector grew in both countries, representing $84.9 \%$ in Italy and $83.9 \%$ in Chile, where this concentration is related to a parallel expansion of both high- and low-skilled jobs (Ruiz and Boccardo 2014). The corresponding rates for men are, respectively, only $59.7 \%$ in Italy and $56.9 \%$ in Chile. Similarly, female employment in industry is $12.8 \%$ in Italy and $10.8 \%$ in Chile while farming accounts for a mere $2.3 \%$ in Italy and $5.3 \%$ in Chile. However, in the Chilean case, informal work is more relevant. According to CEPALSTAT, in 2017, it accounted $28.1 \%$ of work in general (lower than the $45.9 \%$ of Latin America), and $32.2 \%$ for women.

In light of the comparative framework presented, the article intends to verify some specific hypotheses.

(1) Despite the differences in the socio-economic development models of the two countries and in the labour market feminization trends, we hypothesize that, while controlling the sectors over time, gender segregation is maintained in both qualified and unskilled services and in traditionally feminized occupations. (2) We expect occupational segregation to be accompanied by a persistent gender pay gap; women continue to earn less than men

\footnotetext{
${ }^{6}$ Retrieved 7 February 2020, from the CEPALSTAT Interact website: https://estadisticas.cepal.org/cepal stat/tabulador/ConsultaIntegrada.asp?idIndicador=2679\&idioma=e.

7 The low gender pay gap for Italy is connected to the lower level of female employment and the over-representation of employees with a high level of education. In other words, there are fewer women employed in sectors with a low level of qualification and pay.

8 The data are based on the common OECD definition of part-time employment as equivalent to people habitually working less than $30 \mathrm{~h}$ a week in their main job (OECD 2019).

9 Retrieved 7 February 2020, from OECD. Stat Interact website: https://stats.oecd.org/Index.aspx
} 
both because they are employed in different occupations and because of discrimination effects for the same productivity. The pay gap persists even when controlling for some possible confounders, such as part-time work, educational attainment and age.

\section{Data and Methods}

With the aim of evaluating gender segregation in the labour market, we used one heterogeneity index — the Women and Employment Index (WEI)—which measures the different presence of men and women within a specific classification of occupational groups.

$$
\begin{gathered}
\text { WEI }=2 \mathrm{DM} / \mathrm{N} \\
\text { with }: D=0.5 \Sigma|F i / F-M i / M|
\end{gathered}
$$

where $\mathrm{F}$ and $\mathrm{M}$ are the total number of woman and men, $\mathrm{N}$ the total number of cases, $\mathrm{D}$ the Duncan Segregation Index, and $\mathrm{F}_{\mathrm{i}}$ and $\mathrm{M}_{\mathrm{i}}$ the number of women and men employed in the occupational category $i$, The $\mathrm{D}$ Index is a classical and well-known index of segregation, widely used in labour market gender segmentation analysis, whose range-between 0 (minimum segregation) and 1 (maximum segregation) - is half the sum of the absolute differences between the male and female coefficients of representativeness calculated for each occupation (Duncan and Duncan 1959). The WEI, on the other hand, is a slightly modified version of the $\mathrm{D}$ index where $\mathrm{M} / \mathrm{N}$ is the share of men employed out of the total workforce. The WEI index diverges significantly from D only if the ratio of male and female workers varies considerably (Siltanen et al. 1995). In particular, feminization in Chile has increased significantly in recent years, thus we will adopt the WEI index to describe the trend in gender segregation.

Although there is a wide debate on advantages and disadvantages of gender segregation indices (see Grusky and Charles 1998), and there are alternative indices such as those proposed by Karmel and MacLachlan (1988) and Charles and Grusky (2004), we decided to use WEI mainly for two reasons: first, because its widespread use allows us comparability with other research results and, second, it allows adjusting time variations in the ratio of male and female workers (in particular, this is important for the Chilean case).

We applied these indices to the Labour Force Surveys in Italy from 1992 to 2017. It is important to consider that there are two breaks in the Italian data: a significant change took place between 2003 and 2004, when the survey was harmonized according to the European standards (Eurostat 2009); a second, less relevant change occurred from 2010 to 2011 when the ISCO88 classification was replaced by ISCO08 (ISTAT 2013). In the Chilean case, we used the National Socioeconomic Characterization Survey (CASEN) from 1992 to 2017 (data for 1992, 1994, 1996, 1998, 2000, 2003, 2005, 2009, 2011, 2013, 2015 and 2017).

Labour market segmentation stems from the combination of two fundamental characteristics of employment: the classification of occupations and economic sectors. We decided to adopt the ISCO classification (ISCO08) while only considering the first digit, and ad hoc classification of the economic sector. In particular, the classification of the economic sector focuses on the tertiary sub-sectors, distinguishing between Traditional tertiary activities, Advanced activities, Public administration and Health \& education. This choice is motivated by the recent process of labour market feminization, concentrated mainly within the occupations in the services sector (see Appendix-Tables 8 and 9). Moreover, in the 
Table 1 Classification of occupation and sector of activity

\begin{tabular}{ll}
\hline ISCO08 (1 digit) & \\
1 & Legislators, senior officials and managers \\
2 & Professionals \\
3 & Technicians and associate professionals \\
4 & Clerks \\
5 & Service workers and shop and market sales workers \\
6 & Skilled agricultural and fishery workers \\
7 & Craft and related trades workers \\
8 & Plant and machine operators and assemblers \\
9 & Elementary occupations \\
Economic sector (Eurostat 2008) \\
I & Primary sector-Agriculture, forestry and fishing (section A) \\
II & Secondary sector-Manufacturing, mining and quarrying and other industry, and \\
& construction (sections B-F) \\
IIIa & Tertiary sector-traditional activities: Wholesale and retail trade, transportation and \\
& storage, accommodation and food service activities (sections G-J) \\
IIIb & Tertiary sector-advanced activities: Financial and insurance activities, real estate \\
& activities, professional, scientific and technical activities (sections K-N) \\
IIIc & Tertiary sector-PA: Public administration (section O) \\
IIId & Tertiary sector-Education, human health and other services (sections P-U) \\
\hline
\end{tabular}

analysis we will also take differences in the economic sectors into account since the horizontal segregation concerns the sectorial distinction of the work activities. According to this definition, it should be noted that we did not consider the difference between employees and self-employed. Differently from vertical indices, horizontal indices give relevance to the distinction of work activities and not to power relations within the labour market. Moreover, the rise of new kinds of autonomous jobs in recent decades (formally independent, but de facto dependent) (Cherry and Aloisi 2016; Semenza and Sarti 2019) do not allow a clear distinction between employees and self-employed (Table 1).

The combination of the two variables generates a segmentation with 48 categories. It should be noted that, due to changes in the classifications across time, the sixth and seventh categories of ISCO have been partially collapsed. In particular, all ISCO 6 occupational groups and all ISCO 7 groups in the primary sector have been collapsed into sector 6-I (see below).

Occupational segregation is the distribution of workers across and within occupations, based on demographic characteristics such as gender; horizontal segregation occurs across occupations, professions and activity sectors, while vertical segregation refers to the hierarchy of occupations within the organization. The literature has shown that high female employment rates are combined with high gender segregation; on the other hand, countries with lower employment rates (such as Italy with respect to the EU average) also show less gender segregation (Emerek et al. 2003).

Segregation in the labour market cannot automatically be considered a disadvantage. Therefore, in our analysis we involve work income, which is the main resource associated with a job. The information collected in the surveys allows us to evaluate the decile of monthly work income. However, this information is only available from 2009, for both countries. We used this variable in two ways: (1) As a dichotomous variable (measuring 


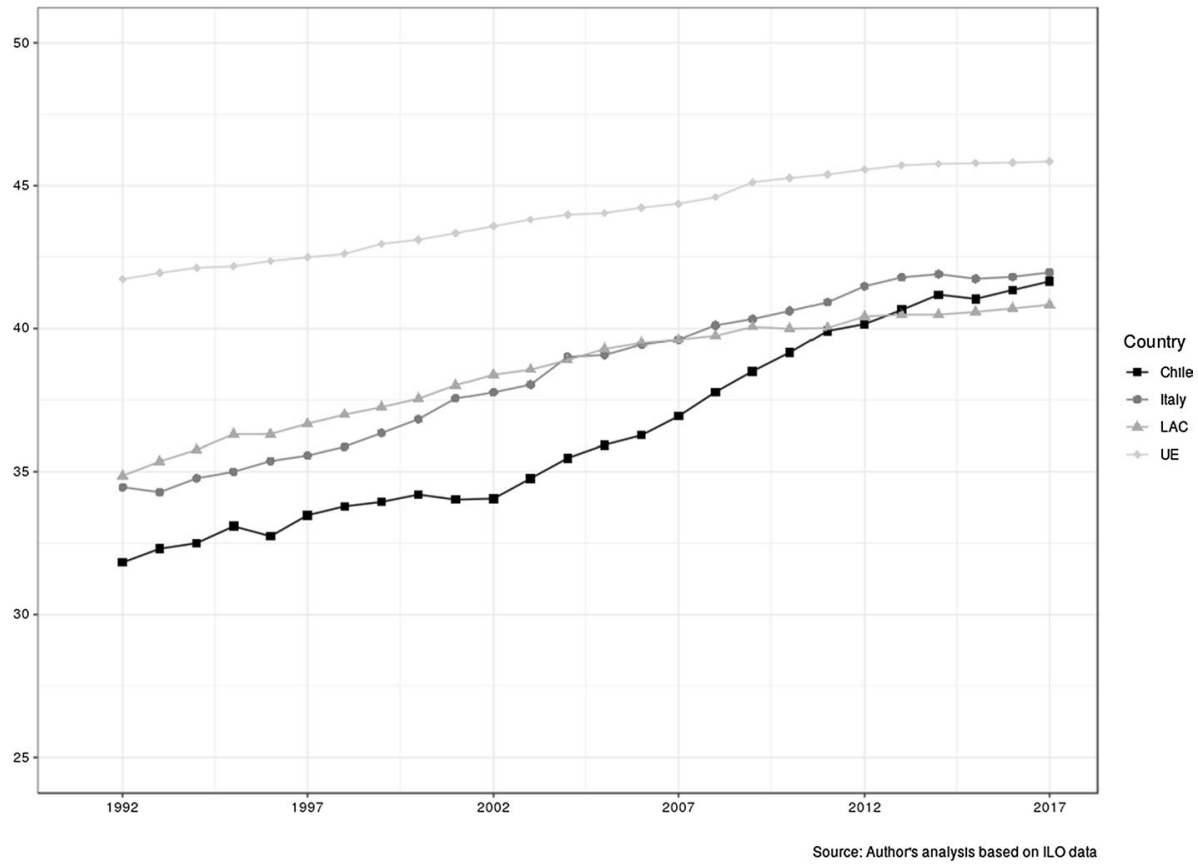

Fig. 1 Women's employment rate (1992-2017). (Source: Author's analysis based on ILO data)

the probability, for men rather than women, of having a work income higher than the 6th decile); (2) As a metric variable, considering the income decile as a scale with a range of $1-10$, where 1 is the lowest decile of income and 10 the highest.

The difference in income decile between men and women in the same occupational segment constitutes a proxy of the wage gap. According to the literature, we expect the differences to benefit the male component of employment. Nevertheless, another aspect should be taken in account, connected to the fact that part-time work is without a doubt more frequent among women. At the same time, different levels of education or seniority at work are associated with different skills and pay. Therefore, we adopted a multivariate regression model in order to control possible confounders such as part-time work, education level and age (as a proxy of seniority). ${ }^{10}$ We used OLS regression because of the uniformity of work income distribution in deciles (Wooldridge 2010). In this analysis, only the main activity sectors need to be considered owing to the size of the occupational groups.

\footnotetext{
10 We operationalized age as a metric variable from 15 to 75 , part-time work as a dichotomous variable ( 0 = full-time, 1 = part-time), and level of education as an ordinal variable with three categories: "Primary and Lower Secondary (ISCED 0-2)", "Upper Secondary (ISCED 3-4)" and “Tertiary (ISCED 5-6)".
} 
Table 2 Women's employment rate by occupational group, sector and country (1992-2017)

\begin{tabular}{|c|c|c|c|c|c|c|c|}
\hline \multicolumn{2}{|c|}{ ISCO Group (1 Digit) } & \multicolumn{3}{|l|}{ Italy } & \multicolumn{3}{|l|}{ Chile } \\
\hline & & \multirow[t]{2}{*}{1992} & \multirow[t]{2}{*}{2017} & \multirow[t]{2}{*}{$\Delta$} & \multirow[t]{2}{*}{1992} & \multirow[t]{2}{*}{2017} & \multirow[t]{2}{*}{$\Delta$} \\
\hline$I S C C$ & (1 digit) & & & & & & \\
\hline 1 & Legislators, senior officials and managers & 16.7 & 27.5 & 10.8 & 30.5 & 45.5 & 15.0 \\
\hline 2 & Professionals & 40.2 & 56.4 & 16.1 & 48.7 & 52.8 & 4.1 \\
\hline 3 & Technicians and associate professionals & 45.4 & 41.0 & -4.4 & 36.6 & 55.6 & 19.0 \\
\hline 4 & Clerks & 50.0 & 65.3 & 15.5 & 57.4 & 64.1 & 6.7 \\
\hline 5 & Service workers and shop and market sales workers & 46.2 & 60.0 & 13.8 & 56.8 & 65.4 & 8.6 \\
\hline 6 & Skilled agricultural and fishery workers & 34.3 & 24.8 & 9.5 & 7.5 & 18.2 & 10.7 \\
\hline 7 & Craft and related trades workers & 16.4 & 11.0 & 5.4 & 14.8 & 13.8 & -0.9 \\
\hline 8 & Plant and machine operators and assemblers & 17.7 & 17.0 & -0.7 & 5.3 & 7.2 & 1.9 \\
\hline 9 & Elementary occupations & 40.9 & 46.0 & 5.2 & 26.3 & 45.8 & 19.5 \\
\hline \multicolumn{8}{|c|}{ Activity sector } \\
\hline I & Primary & 37.7 & 27.6 & -10.1 & 10.1 & 25.0 & 14.9 \\
\hline II & Secondary & 22.0 & 20.9 & -1.1 & 17.1 & 16.3 & -0.8 \\
\hline IIIa & Tertiary (traditional) & 34.1 & 40.5 & 6.4 & 34.3 & 44.5 & 10.2 \\
\hline IIIb & Tertiary (advanced) & 36.3 & 48.0 & 11.7 & 36.2 & 44.0 & 7.8 \\
\hline IIIc & Public administration & 35.1 & 43.6 & 8.5 & 32.7 & 46.1 & 13.4 \\
\hline IIId & Education, human health and other services & 59.3 & 72.5 & 13.2 & 63.1 & 74.4 & 11.3 \\
\hline
\end{tabular}

\section{Female Employment Rates and Occupational Segregation}

In 1992-2017, women's employment participation rates rose in both Chile and Italy (Fig. 1). Whereas Chile grew by $9.6 \%$, the figure in Italy rose by $7.5 \%$. Nevertheless, the female participation rates in both countries are below the European Union average, but slightly higher than the Latin American and Caribbean (LAC) rates. Since 2002, the rate of female employment has grown rapidly in Chile, reaching the Italian figure $(41.7 \%$ versus $42.0 \%$ ).

In general terms, there is a gender gap in the composition of the main occupational groups and activity sectors in both countries (Table 2).

Between 1992 and 2017, the female employment rate in Chile grew in almost all occupational groups, while in Italy the rate only increased for directors, professionals, clerks, service and sales workers, and elementary occupations. In 2017, in Chile women made up the majority (over 50\%) of service and sales workers, clerks, technicians and professionals. Whereas in Italy, women formed the majority of clerks, service and sales workers, and professionals. An increase in the women's employment rate in all the tertiary sectors can be observed in both countries (Table 2). However, women are strongly concentrated in low-skilled services or, if highly skilled, they are mainly employed in occupations linked to the health or education sectors. In fact, in 2017, in both countries, the women's employment rate was only greater than 50\% in Sector IIId (Education, human health and other services).

To summarize, in these 25 years women's employment rates mainly rose in all of the tertiary sectors (IIIa-IIId): in low-skill occupations such as clerks, service and sales workers, and high-skill occupations, such as professionals (and in Chile also technicians). 
Table 3 Women's employment rates in occupational groups and sectors, by country (1992-2017)

\begin{tabular}{|c|c|c|c|c|c|c|c|}
\hline \multirow[t]{2}{*}{ ISCO } & \multirow[t]{2}{*}{ Sector } & \multicolumn{3}{|l|}{ Italy } & \multicolumn{3}{|l|}{ Chile } \\
\hline & & 1992 & 2017 & $\Delta$ & 1992 & 2017 & $\Delta$ \\
\hline \multicolumn{8}{|c|}{ Legislators, senior officials and managers } \\
\hline 1 & Primary & 29.5 & 33.8 & 4.3 & 7.7 & 22.0 & 14.3 \\
\hline 1 & Secondary & 11.3 & 16.3 & 5.0 & 18.2 & 21.7 & 3.5 \\
\hline 1 & Tertiary traditional & 23.2 & 27.3 & 4.1 & 38.3 & 52.5 & 14.2 \\
\hline 1 & Tertiary advanced & 12.4 & 29.0 & 16.6 & 23.9 & 25.4 & 1.5 \\
\hline 1 & Public administration & 25.4 & 40.1 & 14.7 & 14.3 & 35.5 & 21.2 \\
\hline 1 & Education, human health and other services & 21.0 & 46.6 & 25.6 & 31.6 & 57.2 & 25.6 \\
\hline \multicolumn{8}{|c|}{ Professionals } \\
\hline 2 & Primary & - & 40.0 & 40.0 & 15.7 & 28.7 & 12.9 \\
\hline 2 & Secondary & 17.4 & 26.1 & 8.7 & 15.7 & 22.3 & 6.7 \\
\hline 2 & Tertiary traditional & 33.1 & 38.8 & 5.7 & 31.6 & 36.9 & 5.3 \\
\hline 2 & Tertiary advanced & 21.5 & 38.6 & 17.1 & 30.2 & 38.4 & 8.2 \\
\hline 2 & Public administration & 35.7 & 49.1 & 13.4 & 48.2 & 52.7 & 4.5 \\
\hline 2 & Education, human health and other services & 47.6 & 70.7 & 23.1 & 62.3 & 66.2 & 4.0 \\
\hline \multicolumn{8}{|c|}{ Technicians and associate professionals } \\
\hline 3 & Primary & 29.0 & 34.6 & 5.6 & 12.3 & 25.7 & 13.4 \\
\hline 3 & Secondary & 24.8 & 23.7 & -1.1 & 16.1 & 28.9 & 12.8 \\
\hline 3 & Tertiary traditional & 30.5 & 26.6 & -3.9 & 26.7 & 43.8 & 17.1 \\
\hline 3 & Tertiary advanced & 32.6 & 40.2 & 7.6 & 33.6 & 51.1 & 17.6 \\
\hline 3 & Public administration & 43.4 & 38.9 & -4.5 & 34.8 & 51.8 & 17.0 \\
\hline 3 & Education, human health and other services & 71.4 & 68.5 & -2.9 & 56.9 & 74.3 & 17.5 \\
\hline \multicolumn{8}{|l|}{ Clerks } \\
\hline 4 & Primary & 49.1 & 63.9 & 14.8 & 45.1 & 49.4 & 4.3 \\
\hline 4 & Secondary & 47.6 & 59.3 & 11.7 & 50.4 & 40.6 & -9.8 \\
\hline 4 & Tertiary traditional & 45.2 & 56.0 & 10.8 & 54.5 & 61.7 & 7.2 \\
\hline 4 & Tertiary advanced & 53.8 & 74.5 & 20.7 & 55.5 & 70.9 & 15.3 \\
\hline 4 & Public administration & 46.5 & 64.5 & 18.1 & 62.1 & 70.6 & 8.5 \\
\hline 4 & Education, human health and other services & 61.9 & 75.8 & 13.9 & 72.5 & 79.8 & 7.3 \\
\hline \multicolumn{8}{|c|}{ Service workers and shop and market sales workers } \\
\hline 5 & Primary & 34.2 & 33.3 & -0.8 & 23.3 & 37.2 & 13.9 \\
\hline 5 & Secondary & 36.4 & 62.0 & 25.6 & 51.4 & 58.9 & 7.6 \\
\hline 5 & Tertiary traditional & 47.6 & 55.5 & 7.9 & 52.6 & 61.5 & 8.9 \\
\hline 5 & Tertiary advanced & 34.8 & 40.4 & 5.7 & 29.9 & 34.3 & 4.3 \\
\hline 5 & Public administration & 12.5 & 15.6 & 3.1 & 16.1 & 24.4 & 8.4 \\
\hline 5 & Education, human health and other services & 60.3 & 81.7 & 21.4 & 80.8 & 86.8 & 6.0 \\
\hline \multicolumn{8}{|c|}{ Skilled agricultural and fishery workers } \\
\hline 6 & Primary & 34.3 & 24.8 & -9.5 & 7.5 & 18.2 & 10.7 \\
\hline \multicolumn{8}{|c|}{ Craft and related trades workers } \\
\hline 7 & Secondary & 17.6 & 10.2 & -7.3 & 16.9 & 12.3 & -4.6 \\
\hline 7 & Tertiary traditional & 10.2 & 7.7 & -2.6 & 14.0 & 20.3 & 6.4 \\
\hline 7 & Tertiary advanced & 18.9 & 17.1 & -1.8 & 9.1 & 8.5 & -0.6 \\
\hline 7 & Public administration & 9.7 & 1.8 & -7.9 & - & 9.6 & 9.6 \\
\hline 7 & Education, human health and other services & 22.3 & 35.4 & 13.2 & 5.0 & 15.7 & 10.7 \\
\hline
\end{tabular}


Table 3 (continued)

\begin{tabular}{|c|c|c|c|c|c|c|c|}
\hline \multirow[t]{2}{*}{ ISCO } & \multirow[t]{2}{*}{ Sector } & \multicolumn{3}{|l|}{ Italy } & \multicolumn{3}{|l|}{ Chile } \\
\hline & & 1992 & 2017 & $\Delta$ & 1992 & 2017 & $\Delta$ \\
\hline \multicolumn{8}{|c|}{ Plant and machine operators and assemblers } \\
\hline 8 & Primary & 7.0 & 13.6 & 6.6 & 3.3 & 8.4 & 5.1 \\
\hline 8 & Secondary & 25.4 & 21.5 & -3.9 & 9.8 & 8.6 & -1.2 \\
\hline 8 & Tertiary traditional & 1.8 & 4.4 & 2.6 & 2.3 & 5.9 & 3.6 \\
\hline 8 & Tertiary advanced & 11.6 & 39.8 & 28.2 & - & 7.6 & 7.6 \\
\hline 8 & Public administration & 2.8 & 3.3 & 0.4 & - & 3.6 & 3.6 \\
\hline 8 & Education, human health and other services & 16.4 & 21.2 & 4.8 & 7.0 & 13.1 & 6.1 \\
\hline \multicolumn{8}{|c|}{ Elementary occupations } \\
\hline 9 & Primary & 48.7 & 30.4 & -18.4 & 11.3 & 31.4 & 20.1 \\
\hline 9 & Secondary & 16.5 & 17.8 & 1.3 & 8.2 & 13.1 & 4.9 \\
\hline 9 & Tertiary traditional & 27.4 & 23.5 & -3.9 & 17.4 & 46.2 & 28.8 \\
\hline 9 & Tertiary advanced & 55.4 & 60.5 & 5.1 & 13.7 & 42.9 & 29.2 \\
\hline 9 & Public administration & 35.6 & 23.3 & -12.4 & 6.5 & 46.1 & 39.6 \\
\hline 9 & Education, human health and other services & 60.6 & 77.7 & 17.1 & 79.1 & 79.7 & 0.7 \\
\hline
\end{tabular}

When analysing female employment rates by activity sector, we observe some differences within and between the two countries as well as many similarities (Table 3).

In high-skill occupations (ISCO 1-3) — such as legislators, senior officials, managers and professionals-female employment rates increased in all sectors and in both countries (with a special strength in the service sector). On the other hand, we notice that women are highly concentrated in only two sectors (Education, human health, other services and Public administration) while they are under-represented in the advanced tertiary sector, with few exceptions.

It is possible to observe the same growth trend for medium- and low-skill occupations (such as clerks, service and sales workers), with women's employment growing in all activity sectors (except for clerks in sector II in Chile, and sales workers in sector I in Italy). Indeed, in 2017 in Italy women made up the majority of clerks in all sectors, and the structure of women's employment within service and sales activities was similar in both countries.

In low-skill occupations - such as elementary occupations (ISCO 9)—women's employment decreased almost everywhere in Italy but not in Chile, except for Education, health and other services, where women represent the large majority.

In short, from a general point of view it can be said that, although female employment rates increased in the period under consideration, with a strong acceleration in Chile, gender segregation is maintained in some service sectors, both for qualified profiles and for medium- to low-skill occupations. 


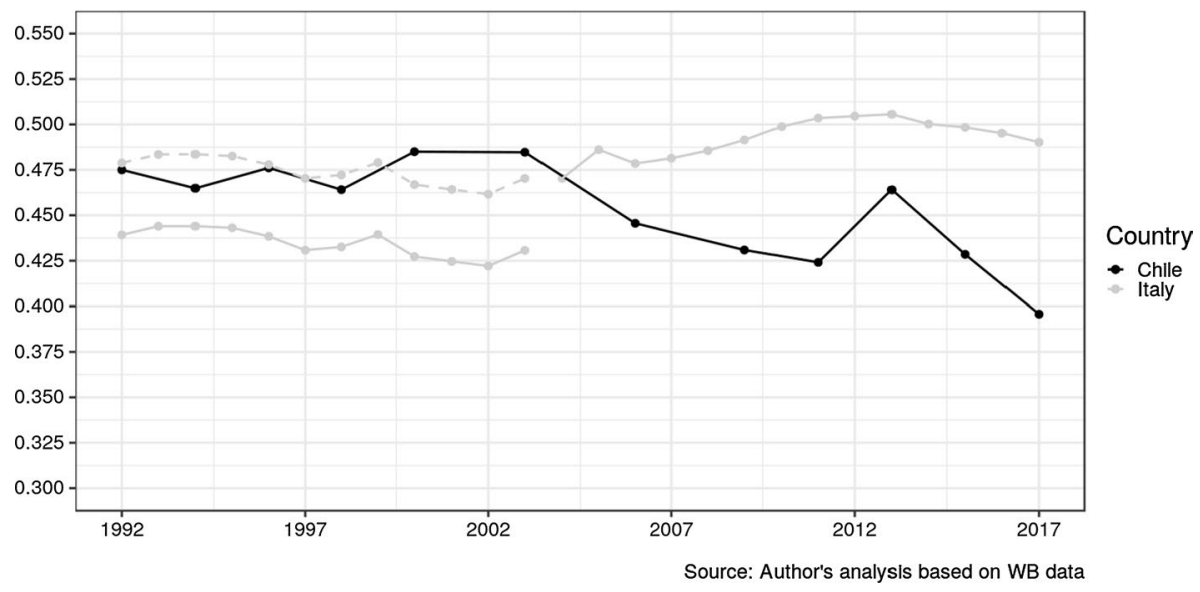

Fig. 2 Women and Employment Index (WEI) trend by country (1992-2017). (Source: Author's analysis based on WB data)

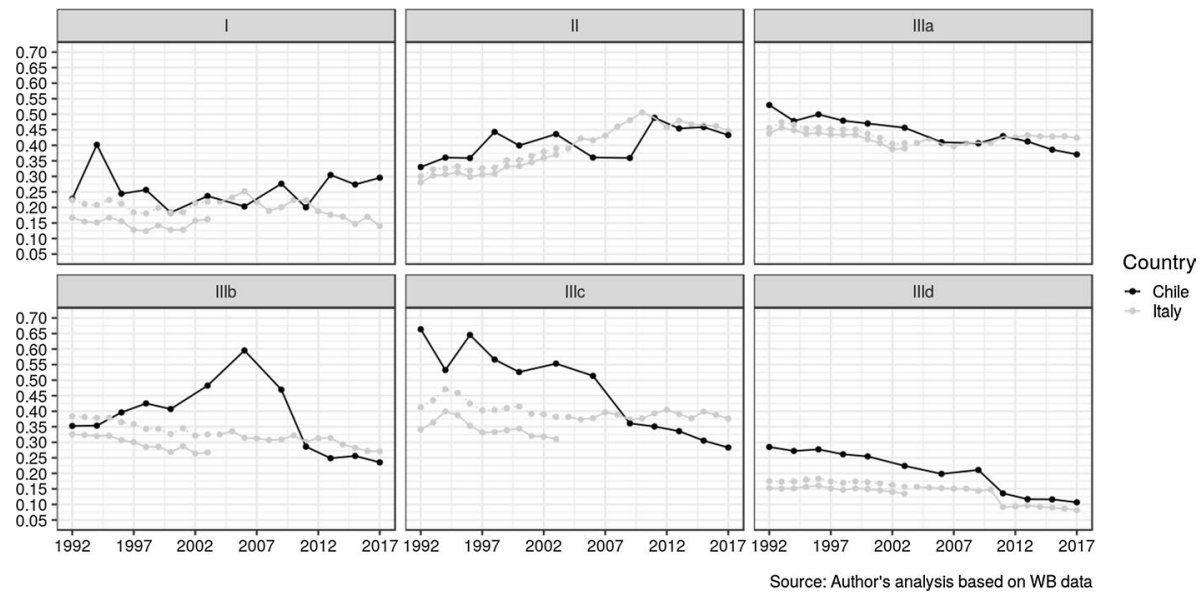

Fig. 3 Women and Employment Index (WEI) trend by activity sector (1992-2017). (Source: Author's analysis based on WB data)

Figure 2 shows the Women and Employment Index (WEI) trends for both countries. ${ }^{11}$ As we can see, the WEI showed similar trajectories and some specific peculiarities between 1992 and 2017 (Fig. 2). ${ }^{12}$ While in Italy the WEI was stable in the period 1992-2003 (around 0.33 or 0.47 ), in Chile it grew from 0.47 to 0.48 . Thereafter, in Italy

${ }^{11}$ Because of the methodological break in the Italian series from 2003 to 2004 (see above), we can reasonably assume that segregation in 2003 was the same as in 2004 (or similar), since there are no socioeconomic reasons for an important change. If this is true, for Italy we have to refer to the dashed line rather than the continuous line in Fig. 2. Otherwise, we have to consider two different periods, but the general interpretation of the trend does not change.

12 All WEI differences analyzed in this study are statistically significant $(p<0.05)$. General WEI Confidence intervals (95\%) are in Appendix-Table 10. 


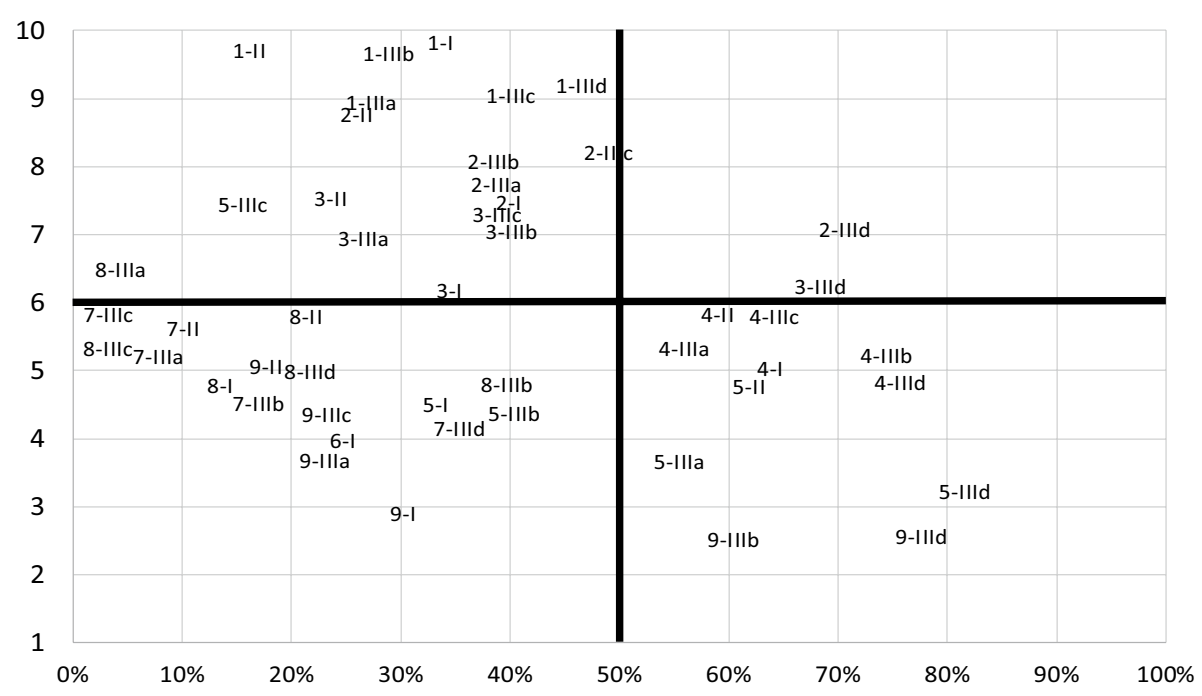

Fig. 4 Feminization rate and average income decile, by occupational group (Italy, 2017)

the WEI grew until stabilizing at 0.51 in 2013 and after that decreased to 0.49 in 2017 , whereas in Chile the index decreased from 0.48 to 0.42 in 2003-2011, then it rose to 0.46 in 2013, and finally it started to decrease again to 0.40 in 2017 (the lowest level reached in the period considered).

The difference between countries (WEI 0.09 in 2017) may depend on the rapid feminization of employment in Chile with respect to Italy (Fig. 1), which included more women professionals and technicians in the tertiary sector (Table 2), due to an increase in average education levels (Orellana 2011). Therefore, as the comparative analysis showed, labour market feminization, combined with higher levels of education, can reduce gender segregation. To continue the analysis, we consider the WEI by activity sector (Fig. 3).

Firstly, it is useful to remember that, as explained above, the index is built by taking into account the dynamics of growth in female employment. Secondly, as a general trend, we can observe that the disparity index (WEI) remains substantially stable in the primary and secondary sectors. However, it is interesting to observe the tertiary sectors, where, as we have seen, the great majority of female employment is concentrated. Two trends stand out with particular intensity. One is that, while the index remains high in the traditional lowskill services, they drop significantly in the most qualified tertiary sectors, a sign that the level of qualification and education contributes to decreasing gender segregation. The second is the difference between the countries: while the index is substantially stable in Italy, it decreases a lot in Chile, especially in the Public administration (from 0.66 to 0.28 ) and in the Advanced services sector (from 0.35 to 0.24). In Sector IIId (Education, health and other services) both countries display similar trajectories and in 2017 it reached the lowest WEI of all the sectors (in Chile the WEI dropped sharply from 0.29 to 0.11 and in Italy from 0.18 to 0.08 ). As could be expected, the industrial sector is the one that maintains the highest and most persistent gender dissimilarity index.

In summary, between 1992 and 2017 the WEI showed a similar path in the tertiary and secondary sectors. However, the decrease of the WEI in the tertiary sector shows that 


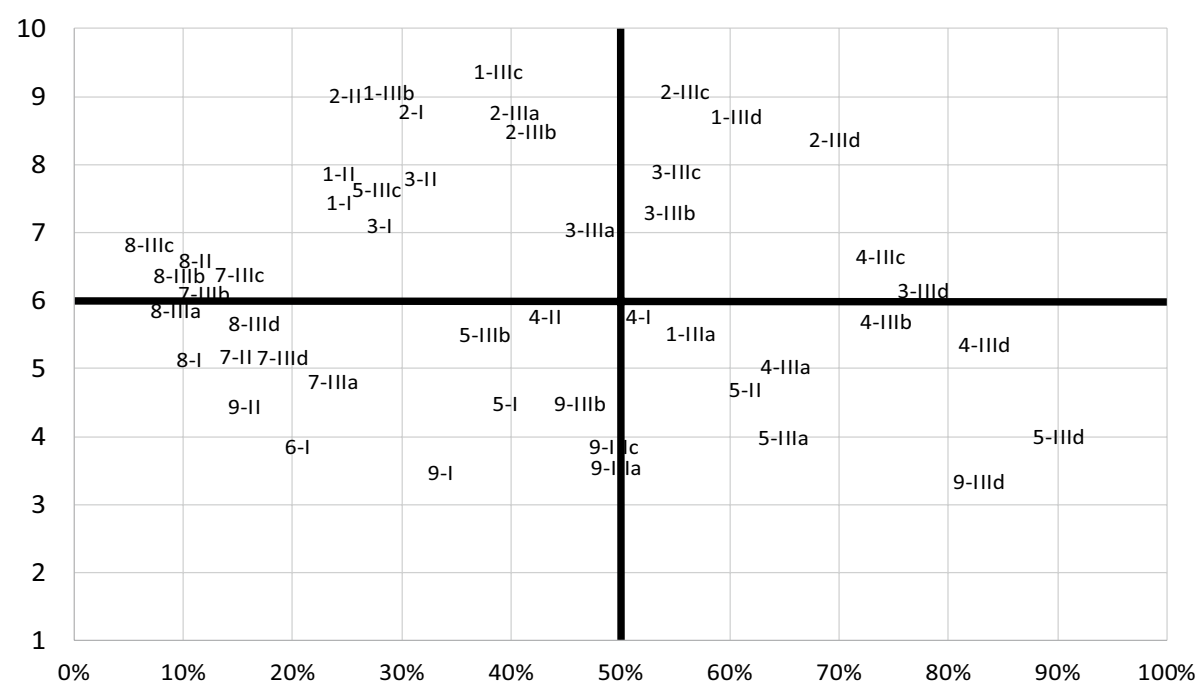

Fig. 5 Feminization rate and average income decile, by occupational group (Chile, 2017)

segregation had been falling, but always within occupational groups and activity sectors traditionally occupied by women.

\section{Segregation and the Gender Pay Gap}

As was assumed in the initial part of the article, there is an association between gender employment segregation and the gender pay gap. Figures 4 and 5 show the relationship between the feminization of the 48 occupational groups and the average income decile in $2017 .^{13}$

With respect to the y-axis, many segments of the Elementary occupations (ISCO 9) and low-skilled Services workers (ISCO 5) are at the bottom of the scatter plots, where incomes are lower, while managers, professionals and high-skill jobs are at the top (ISCO 1 or 2). In the middle, we can find more or less all the other groups. With respect to the x-axis, the left side of the scatter plot shows the segments with a high proportion of males, while the right side shows the occupational segments with a higher proportion of females, namely the more feminized jobs. The first are manual occupations in various sectors (ISCO 7, 8 or 9) and the occupations on the left are mainly tertiary jobs (ISCO 4 or 5).

As we can see, the general configuration is similar in both countries. Nevertheless, it is very interesting to note that for Italy the second quadrant, on the top-right, is substantially empty. In this quadrant, we find the feminized jobs with the highest incomes, but there are only two professional groups, which are moreover positioned very low down (2-IIId and 3-IIId), associated with health and education professionals and technicians (professors, doctors, teachers and specialized nurses). In Chile, on the other hand, the same quadrant is more populated; some occupational segments are much more to the left (ISCO 1, 2 or 3). The scatter charts suggest

13 The occupational groups with less than 50 valid cases were not considered. 
Table 4 Beta coefficients (OLS) on income decile from 2009 to 2017 by sector and sex (Chile and Italy)

\begin{tabular}{|c|c|c|c|c|c|c|c|c|c|c|c|c|}
\hline \multirow[t]{3}{*}{ Sector } & \multicolumn{6}{|l|}{ Chile } & \multicolumn{6}{|l|}{ Italy } \\
\hline & \multicolumn{2}{|l|}{2009} & \multicolumn{2}{|l|}{2017} & \multicolumn{2}{|c|}{ Gender gap } & \multicolumn{2}{|l|}{2009} & \multicolumn{2}{|l|}{2017} & \multicolumn{2}{|c|}{ Gender gap } \\
\hline & M & $\mathrm{F}$ & M & F & 2009 & 2017 & M & F & M & $\mathrm{F}$ & 2009 & 2017 \\
\hline I & $0.00^{\mathrm{a}}$ & -0.81 & $0.00^{\mathrm{a}}$ & -0.75 & 0.81 & 0.75 & $0.00^{\mathrm{a}}$ & -1.26 & $0.00^{\mathrm{a}}$ & -0.81 & 1.26 & 0.81 \\
\hline II & 1.46 & -0.05 & 1.15 & -0.20 & 1.51 & 1.35 & 1.73 & 0.62 & 2.19 & 1.23 & 1.11 & 0.96 \\
\hline IIIa & 1.30 & 0.08 & 0.70 & -0.47 & 1.22 & 1.18 & 1.69 & 0.51 & 1.75 & 0.76 & 1.18 & 0.99 \\
\hline IIIb & 1.36 & 0.85 & 1.44 & 0.70 & 0.52 & 0.75 & 2.09 & 0.86 & 1.99 & 1.05 & 1.23 & 0.94 \\
\hline IIIIc & 1.61 & 0.50 & 1.87 & 1.06 & 1.12 & 0.81 & 2.06 & 1.18 & 2.01 & 1.21 & 0.89 & 0.80 \\
\hline IIId & 0.98 & -0.46 & 0.94 & 0.01 & 1.44 & 0.93 & 1.39 & 0.58 & 1.15 & 0.46 & 0.80 & 0.70 \\
\hline
\end{tabular}

Controlled by age, part-time work and educational level

${ }^{\mathrm{a} C}$ Categories of reference

Table 5 Beta coefficients (OLS) on income decile from 2009 to 2017 by occupation and sex (Chile and Italy)

\begin{tabular}{|c|c|c|c|c|c|c|c|c|c|c|c|c|}
\hline \multirow[t]{3}{*}{ ISCO } & \multicolumn{6}{|l|}{ Chile } & \multicolumn{6}{|l|}{ Italy } \\
\hline & \multicolumn{2}{|l|}{2009} & \multicolumn{2}{|l|}{2017} & \multicolumn{2}{|c|}{ Gender gap } & \multicolumn{2}{|l|}{2009} & \multicolumn{2}{|l|}{2017} & \multicolumn{2}{|c|}{ Gender gap } \\
\hline & M & $\mathrm{F}$ & M & $\mathrm{F}$ & 2009 & 2017 & M & $\mathrm{F}$ & M & $\mathrm{F}$ & 2009 & 2017 \\
\hline 1 & $0.00^{\mathrm{a}}$ & -0.78 & $0.00^{\mathrm{a}}$ & -1.58 & 0.78 & 1.58 & $0.00^{\mathrm{a}}$ & -0.58 & $0.00^{\mathrm{a}}$ & -0.35 & 0.58 & 0.35 \\
\hline 2 & -0.22 & -0.78 & 0.71 & 0.35 & 0.56 & 0.36 & -0.88 & -1.58 & -0.90 & -2.00 & 0.69 & 1.10 \\
\hline 3 & -0.78 & -1.94 & -0.08 & -1.15 & 1.16 & 1.06 & -1.26 & -2.34 & -1.23 & -2.18 & 1.08 & 0.96 \\
\hline 4 & -1.37 & -2.55 & -1.01 & -1.92 & 1.18 & 0.91 & -2.10 & -2.98 & -2.33 & -3.05 & 0.88 & 0.72 \\
\hline 5 & -1.83 & -3.13 & -1.70 & -2.88 & 1.31 & 1.18 & -2.62 & -3.90 & -2.91 & -4.14 & 1.29 & 1.23 \\
\hline 6 & -2.56 & -3.55 & -2.46 & -3.37 & 0.98 & 0.91 & -3.85 & -5.02 & -4.03 & -4.63 & 1.17 & 0.61 \\
\hline 7 & -1.50 & -3.36 & -1.30 & -3.35 & 1.86 & 2.04 & -2.80 & -4.40 & -2.64 & -3.91 & 1.60 & 1.27 \\
\hline 8 & -1.32 & -2.78 & -0.79 & -2.02 & 1.46 & 1.23 & -2.26 & -4.01 & -2.15 & -3.53 & 1.76 & 1.38 \\
\hline 9 & -3.34 & -4.25 & -2.44 & -3.10 & 0.91 & 0.66 & -3.88 & -4.96 & -3.89 & -4.82 & 1.08 & 0.93 \\
\hline
\end{tabular}

Controlled by age, part-time work and educational level

${ }^{\mathrm{a}}$ Reference categories

that the gender pay gap is more marked in Italy than in Chile. If we consider the overall probability, for a man rather than a woman, of having a work income above the 6th decile, in Italy in 2017 this probability was 0.19 , instead in Chile it was only 0.10 .

These probabilities are constant over time, from 2009 to 2017 (the period for which data on job earnings are available). In particular, the detailed probability differences between the occupational segments highlight some interesting aspects (see Appendix, Table 11).

In both countries, women systematically have lower pay than men. In particular, the pay gap seems higher in the secondary sector of industry and manufacturing (II) and in the traditional (IIIa) and advanced (IIIb) tertiary sectors, and lower in the public administration sector and in health and education activities (IIIc and IIId), as was obvious to expect. Moreover, the pay gap is higher in the intermediate ISCO categories (technicians, clerks, service and sales workers), while it is lower both among the most qualified occupations (legislators, senior official managers and professionals) and among the elementary occupations. 


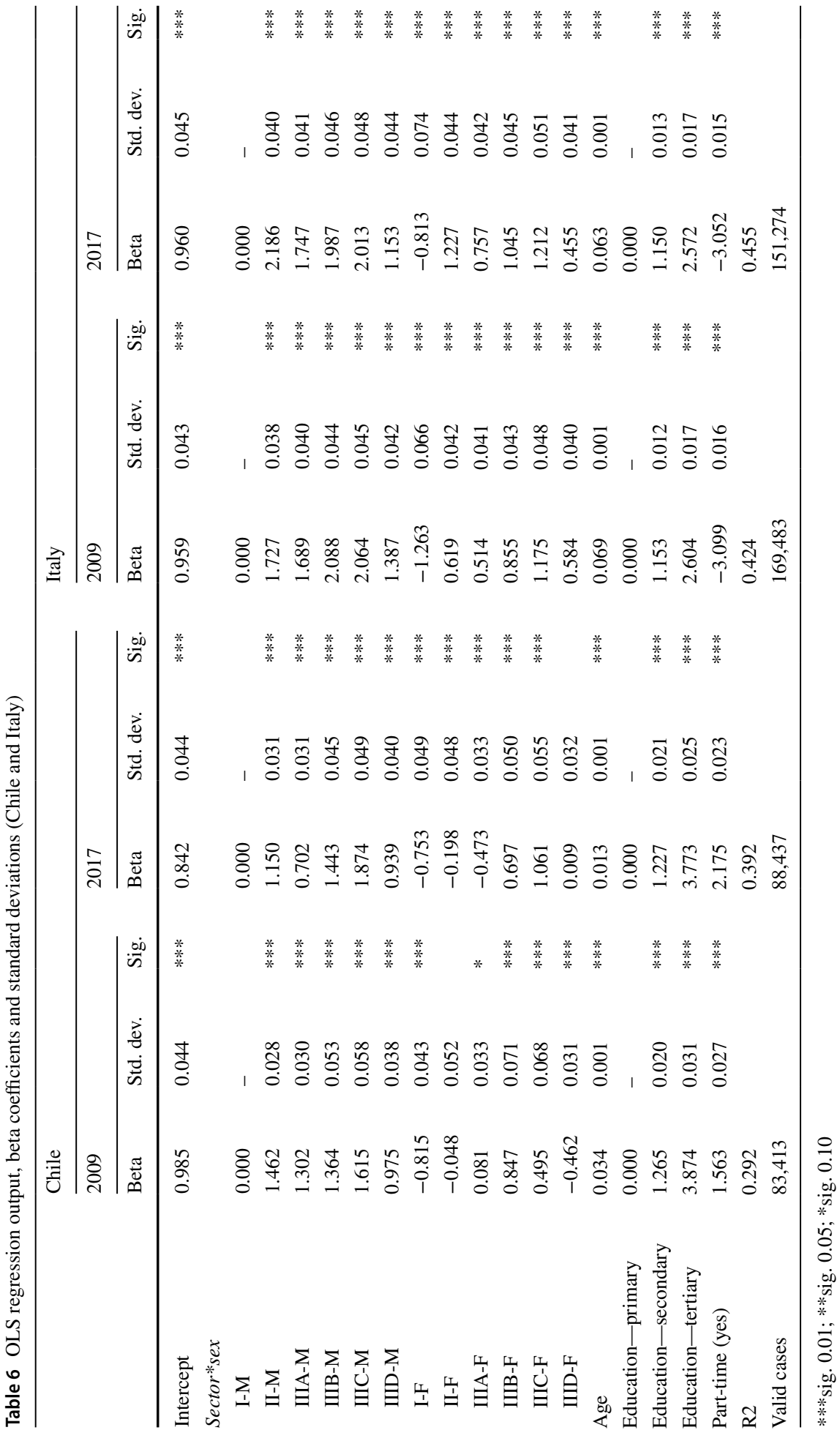




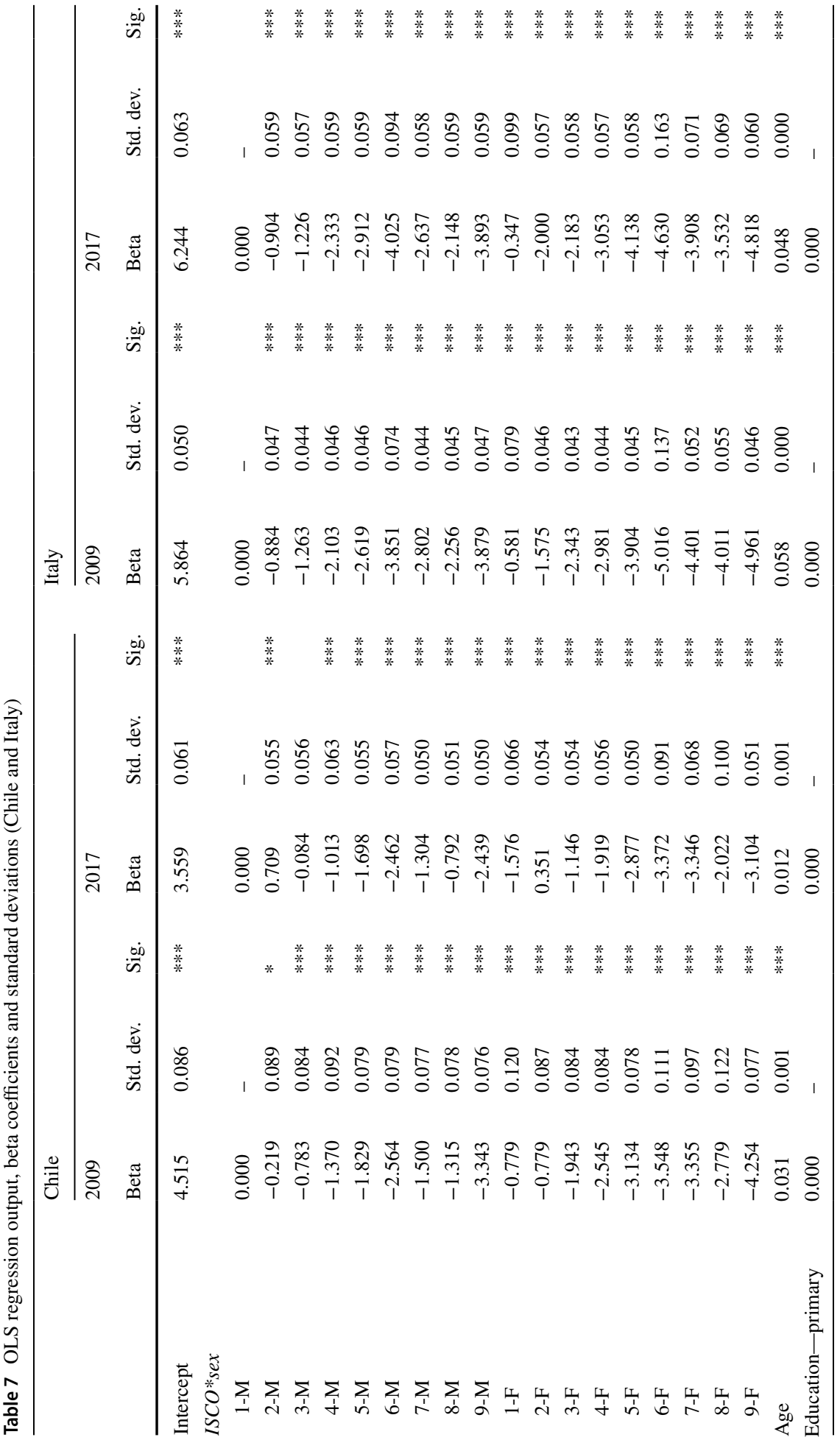




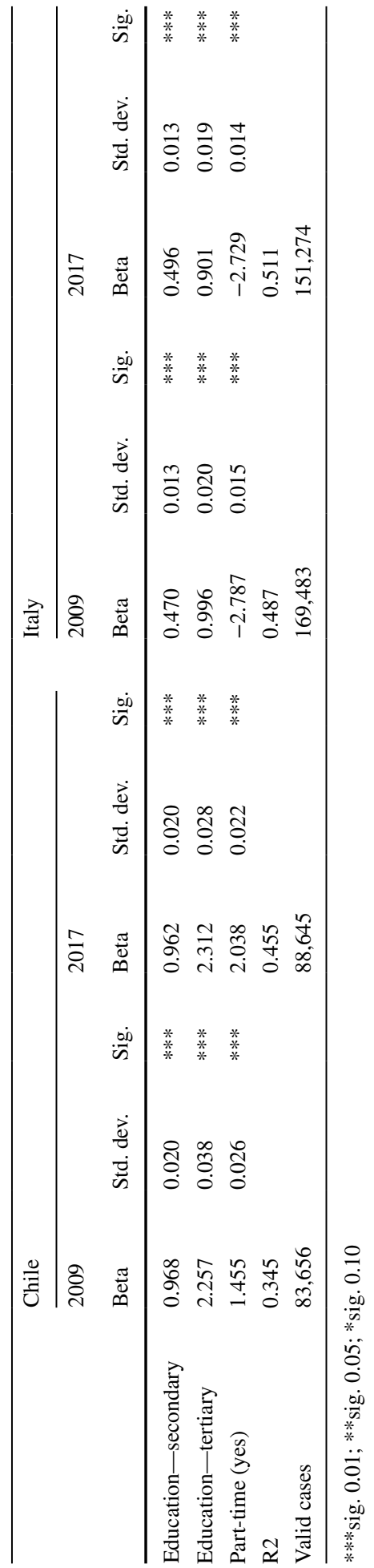


The gender pay gap maintains its shape even when controlling for age, part-time work and educational attainment, as emerged from the framework previously described.

However, some possible confounders could change the pay gap since part-time work, age and educational level could interact in the income distribution. Thus, we applied a multivariate regression model to take these potential biases into account.

Tables 4 and 5 show a synthesis of the results of the OLS regression models (see Tables 6 and 7) ${ }^{14}$ and the differentials in the effects of having a higher decile with respect to the reference category (males employed in the primary sector). Positive differences mean that the effect of the activity sector on earnings is beneficial for men. As an example, in 2009 in the secondary sector (Industry), Chilean men had on average 1.51 deciles more than women (ceteris paribus age, part-time work and educational attainment).

All the differentials are positive and similar from 2009 to 2017: in particular, the highest difference for Chile is in the secondary sector, both in 2009 and 2017. For Italy, the differences are quite similar among all sectors, except for Health and education activities where the gap is lower. ${ }^{15}$ The pay gap analysis - considering the differentials among the ISCO categories-shows similar results. Just as importantly, the differences are not statistically significant from 2009 to 2017 because the standard errors are higher than the difference itself.

\section{Conclusions}

Therefore, this research provides strong evidence that highlights the importance of comparative analysis to observe similarities and differences in two countries very different in geographical, historical, political and cultural factors. On the one hand, it is possible to observe common elements linked to cultural gender segregation patterns. On the other, the differences in trend could be explained by the specific features and historical moment in which women get in the labour force in both countries. In this sense, the comparative perspective contributes to understanding the variety of labour female insertion in different socioeconomic contexts.

With respect to the initial objectives, the transnational comparative analysis allowed us to investigate some crucial aspects of the gender segmentation of the labour market, showing the persistence of segregation in certain sectors and occupational groups.

The analysis highlighted that the two countries, united by a low presence of women in the labour market, share a significant gender segregation-measured by the dissimilarity index in occupational groups and activity sectors-substantially confirming the first research hypothesis. More than $60 \%$ of women are concentrated in medium- to low-skill occupations. As far as gender segregation by activity sector is concerned, the results show that the primary, secondary and traditional tertiary sectors have a similar gender composition in both countries. The very great majority of women are employed in Education, health and other services, whether they are high-skilled (ISCO 1-3) or in low-skill jobs (ISCO 4-5), with percentages around 70\% in the first case and above $80 \%$ in the second. Nevertheless, in the advanced tertiary sector (IIIb), Public administration (IIIc) and with minor intensity Health and education (IIId), Chile shows a greater decrease in segregation than Italy. Looking at the temporal trend, low-skilled female employment has increased in Italy (ISCO 4) and therefore we can see a deskilling process, while in Chile the growth has mainly occurred in the technical and professional areas.

\footnotetext{
14 The variance inflation factors (VIF) are less than 10 for all variables in the models.

15 The fact that these sectors are mainly public in general guarantees a better level of gender equality in terms of pay and career progression.
} 
Hence, within a similar pattern, there are some differences to be underlined. Over the past 25 years, horizontal gender segregation has remained stable in Italy, while it has decreased slightly in Chile in the last decade. The most recent process of labour market feminization in Chile has probably affected the lower occupational segregation of young (more educated) women entering the labour market. The persistence of gender segregation in Italy instead reflects a crystallized structure of labour market segmentation between women and men, with a more significant impact.

As expected, following our second specific research hypothesis, gender occupational segregation is associated with the gender pay gap, which is wider in Italy. Moreover, the analysis confirms that the activity sectors with a significant prevalence of women are also the sectors where wages are lower. In other words, the more feminised the sectors of activity, the more they tend to be devalued economically, through an average lowering of wages, while the opposite occurs in sectors with a strong male component. On average, the probabilities of a man rather than a woman having an earned income exceeding the 6th decile is 0.19 in Italy and 0.10 in Chile. Even while controlling this association for some possible confounders, such as age, part-time work and educational attainment, the pay gap remained stable over recent years (2009-2017). As we anticipated, wage differentials depend largely on the fact that women and men occupy differently paid sectors and employment positions. However, part of the gender pay gap is attributable to discriminatory behaviour on the part of the demand side, resulting from social stereotypes and business ideology and practices.

Segregation into particular occupations and sectors feeds and is in turn fuelled by cultural stereotypes that prevent efficient use of human resources and undermine the effectiveness of wage equality laws. There are of course mixed economic sectors, but this gender-based occupational segregation is a phenomenon so widespread in all countries that it suggests that the contemporary employment structure is increasingly characterized by an "hyper-segregation" or, said in others terms, marked by real "ghetto occupations" (Charles and Grusky 2004, 2011).

One of the unexpected results of the study is the similarity observed in the two societies around gender segregation in the labour market. In these different societies there seems to be a single, or at least a dominant, model of gender allocation of labour. This substantial uniformity, widely shared between countries, derives from a general value system that governs society and which is functional to a traditional social division of labour.

Despite the increasing inclusion of women in the waged labour market, being a woman, even with the same qualification and at the same level of productivity than men, is still one of the labour supply-side variables, which persists in pre-determining labour market outcomes.

The data provide support for this phenomenon. We envisage that the labour market inequality mechanisms and ranking and sorting processes which tend to reproduce a concentration of women in some both high-skill and low-skill sectors and occupations, are stronger than the national and institutional settings, and become a recurrent universalistic feature crossing both countries and continental borders.

The sexual segregation of labour is impressive for its similar diffusion in different societies and its constancy over time.

Funding Open access funding provided by Università degli Studi di Milano within the CRUI-CARE Agreement.

Open Access This article is licensed under a Creative Commons Attribution 4.0 International License, which permits use, sharing, adaptation, distribution and reproduction in any medium or format, as long as you give appropriate credit to the original author(s) and the source, provide a link to the Creative Commons 
licence, and indicate if changes were made. The images or other third party material in this article are included in the article's Creative Commons licence, unless indicated otherwise in a credit line to the material. If material is not included in the article's Creative Commons licence and your intended use is not permitted by statutory regulation or exceeds the permitted use, you will need to obtain permission directly from the copyright holder. To view a copy of this licence, visit http://creativecommons.org/licenses/by/4.0/.

\section{Appendix}

See Tables 8, 9, 10, and 11 .

Table 8 Percentages of employment by ISCO (1 digit) in 1992 and 2017, all cases and women

\begin{tabular}{|c|c|c|c|c|c|c|c|c|}
\hline \multirow[b]{3}{*}{ ISCO } & \multicolumn{4}{|l|}{ Italy } & \multicolumn{4}{|l|}{ Chile } \\
\hline & \multicolumn{2}{|l|}{ All cases } & \multicolumn{2}{|c|}{$\%$ women } & \multicolumn{2}{|c|}{ All cases } & \multicolumn{2}{|c|}{$\%$ women } \\
\hline & 1992 & 2017 & 1992 & 2017 & 1992 & 2017 & 1992 & 2017 \\
\hline 1 & 2.7 & 2.8 & 2.9 & 1.8 & 4.7 & 4.7 & 5.0 & 5.1 \\
\hline 2 & 6.4 & 14.4 & 11.8 & 18.6 & 5.9 & 11.4 & 10.1 & 14.2 \\
\hline 3 & 16.7 & 17.3 & 24.3 & 16.2 & 4.4 & 9.8 & 5.6 & 12.9 \\
\hline 4 & 10.8 & 11.4 & 16.3 & 17.1 & 5.9 & 6.9 & 11.9 & 10.5 \\
\hline 5 & 16.5 & 19.9 & 22.1 & 27.2 & 12.2 & 15.6 & 24.3 & 24.0 \\
\hline 6 & 6.0 & 2.4 & 1.6 & 1.4 & 10.5 & 5.8 & 2.8 & 2.5 \\
\hline 7 & 21.4 & 13.0 & 5.5 & 3.3 & 15.5 & 13.7 & 8.1 & 4.5 \\
\hline 8 & 8.6 & 7.7 & 3.5 & 3.0 & 7.6 & 8.9 & 1.4 & 1.5 \\
\hline 9 & 10.9 & 11.0 & 12.0 & 11.6 & 33.3 & 23.2 & 30.8 & 25.0 \\
\hline Total & 100.0 & 100.0 & 100.0 & 100.0 & 100.0 & 100.0 & 100.0 & 100.0 \\
\hline $\mathrm{N}$ & 230,140 & 199,898 & 135,162 & 94,978 & 48,927 & 90,820 & 13,912 & 38,531 \\
\hline
\end{tabular}

Table 9 Percentages of employment by economic sector in 1992 and 2017, all cases and women

\begin{tabular}{|c|c|c|c|c|c|c|c|c|}
\hline \multirow[b]{3}{*}{ Sector } & \multicolumn{4}{|l|}{ Italy } & \multicolumn{4}{|l|}{ Chile } \\
\hline & \multicolumn{2}{|l|}{ All cases } & \multicolumn{2}{|c|}{$\%$ women } & \multicolumn{2}{|c|}{ All cases } & \multicolumn{2}{|c|}{$\%$ women } \\
\hline & 1992 & 2017 & 1992 & 2017 & 1992 & 2017 & 1992 & 2017 \\
\hline I & 9.2 & 4.4 & 3.5 & 2.8 & 29.5 & 14.4 & 10.5 & 8.5 \\
\hline II & 33.4 & 25.5 & 14.8 & 12.2 & 24.8 & 20.8 & 14.9 & 8.0 \\
\hline IIIa & 24.4 & 27.5 & 24.0 & 25.5 & 21.5 & 30.3 & 25.9 & 31.7 \\
\hline IIIb & 7.2 & 13.3 & 14.5 & 14.6 & 3.1 & 7.3 & 4.0 & 7.6 \\
\hline IIIc & 7.8 & 5.1 & 5.8 & 5.1 & 2.0 & 5.1 & 2.3 & 5.5 \\
\hline IIId & 17.9 & 24.1 & 37.4 & 39.9 & 19.2 & 22.1 & 42.5 & 38.7 \\
\hline Total & 100.0 & 100.0 & 100.0 & 100.0 & 100.0 & 100.0 & 100.0 & 100.0 \\
\hline $\mathrm{N}$ & 230,140 & 199,898 & 135,162 & 94,978 & 48,927 & 90,820 & 13,912 & 38,531 \\
\hline
\end{tabular}


Table 10 WEI-Confidence intervals at $95 \%$

\begin{tabular}{|c|c|c|c|c|}
\hline \multirow[b]{2}{*}{ Year } & \multicolumn{2}{|l|}{ Italy $^{\mathrm{a}}$} & \multicolumn{2}{|l|}{ Chile } \\
\hline & Lower bound & Upper bound & Lower bound & Upper bound \\
\hline 1992 & 0.475 & 0.482 & 0.471 & 0.479 \\
\hline 1993 & 0.482 & 0.485 & - & - \\
\hline 1994 & 0.482 & 0.485 & 0.461 & 0.469 \\
\hline 1995 & 0.481 & 0.484 & - & - \\
\hline 1996 & 0.476 & 0.480 & 0.472 & 0.481 \\
\hline 1997 & 0.468 & 0.472 & - & - \\
\hline 1998 & 0.470 & 0.474 & 0.460 & 0.468 \\
\hline 1999 & 0.477 & 0.481 & - & - \\
\hline 2000 & 0.465 & 0.469 & 0.482 & 0.488 \\
\hline 2001 & 0.462 & 0.466 & - & - \\
\hline 2002 & 0.460 & 0.463 & - & - \\
\hline 2003 & 0.468 & 0.472 & 0.481 & 0.488 \\
\hline 2004 & 0.468 & 0.472 & - & - \\
\hline 2005 & 0.484 & 0.488 & - & - \\
\hline 2006 & 0.477 & 0.480 & 0.443 & 0.449 \\
\hline 2007 & 0.479 & 0.483 & - & - \\
\hline 2008 & 0.484 & 0.488 & - & - \\
\hline 2009 & 0.489 & 0.494 & 0.428 & 0.434 \\
\hline 2010 & 0.497 & 0.501 & - & - \\
\hline 2011 & 0.501 & 0.506 & 0.421 & 0.428 \\
\hline 2012 & 0.502 & 0.507 & - & - \\
\hline 2013 & 0.503 & 0.508 & 0.461 & 0.467 \\
\hline 2014 & 0.498 & 0.502 & - & - \\
\hline 2015 & 0.496 & 0.501 & 0.426 & 0.431 \\
\hline 2016 & 0.493 & 0.497 & - & - \\
\hline 2017 & 0.488 & 0.492 & 0.393 & 0.399 \\
\hline
\end{tabular}

${ }^{\text {a } W E I ~ a d j u s t e d ~ f r o m ~} 1992$ to 2003 
Table 11 Male-female difference in the probability of having a higher than 6th job income decile in 2017

\begin{tabular}{|c|c|c|c|}
\hline \multicolumn{4}{|c|}{ Gap \% men/women in p>0.6 2017} \\
\hline ISCO & Sector & Italy & Chile \\
\hline 1 & I & $100.0^{\mathrm{a}}$ & $29.5^{\mathrm{a}}$ \\
\hline 1 & II & $3.6^{\mathrm{a}}$ & 22.9 \\
\hline 1 & IIIa & 7.4 & 23.6 \\
\hline 1 & IIIb & -2.4 & 12.0 \\
\hline 1 & IIIc & -5.6 & $-4.0^{\mathrm{a}}$ \\
\hline 1 & IIId & 4.4 & $8.6^{\mathrm{a}}$ \\
\hline 2 & I & $42.9^{\mathrm{a}}$ & -0.5 \\
\hline 2 & II & 9 & 2.5 \\
\hline 2 & IIIa & 22.3 & 8.7 \\
\hline 2 & IIIb & 15.4 & 3.1 \\
\hline 2 & IIIc & 7.2 & 2.1 \\
\hline 2 & IIId & 14.6 & 2.5 \\
\hline 3 & I & $41.4^{\mathrm{a}}$ & $13.7^{\mathrm{a}}$ \\
\hline 3 & II & 26.1 & 16.0 \\
\hline 3 & IIIa & 24.7 & 13.0 \\
\hline 3 & IIIb & 25 & 7.6 \\
\hline 3 & IIIc & 18.1 & 14.8 \\
\hline 3 & IIId & 6.4 & 15.5 \\
\hline 4 & I & $32.9^{\mathrm{a}}$ & $24.5^{\mathrm{a}}$ \\
\hline 4 & II & 27.9 & 25.7 \\
\hline 4 & IIIa & 17.4 & 15.5 \\
\hline 4 & IIIb & 32.1 & 21.5 \\
\hline 4 & IIIc & 13.2 & 14.9 \\
\hline 4 & IIId & 16.7 & 13.9 \\
\hline 5 & I & $17.3^{\mathrm{a}}$ & $17.9^{\mathrm{a}}$ \\
\hline 5 & II & 34.2 & $23.7^{\mathrm{a}}$ \\
\hline 5 & IIIa & 16.1 & 13.0 \\
\hline 5 & IIIb & 19 & $9.1^{\mathrm{a}}$ \\
\hline 5 & IIIc & 21.2 & 19.3 \\
\hline 5 & IIId & 15.3 & 17.2 \\
\hline 6 & I & 9 & $9.8 \%$ \\
\hline 7 & II & 28.8 & 24.7 \\
\hline 7 & IIIa & 21.1 & $28.8^{\mathrm{a}}$ \\
\hline 7 & IIIb & 29.4 & $36.5^{\mathrm{a}}$ \\
\hline 7 & IIIc & $-11.7^{\mathrm{a}}$ & $4.7^{\mathrm{a}}$ \\
\hline 7 & IIId & 24.8 & $7.3^{\mathrm{a}}$ \\
\hline 8 & I & $13.7^{\mathrm{a}}$ & $18.7^{\mathrm{a}}$ \\
\hline 8 & II & 31.7 & $37.7^{\mathrm{a}}$ \\
\hline 8 & IIIa & 40.3 & 12.6 \\
\hline 8 & IIIb & 29.9 & $37.9^{\mathrm{a}}$ \\
\hline 8 & IIIc & $28.0^{\mathrm{a}}$ & $20.8^{\mathrm{a}}$ \\
\hline 8 & IIId & 26.4 & $27.3^{\mathrm{a}}$ \\
\hline 9 & I & 6.4 & $2.8^{\mathrm{a}}$ \\
\hline 9 & II & 16.7 & $6.9^{\mathrm{a}}$ \\
\hline
\end{tabular}


Table 11 (continued)

\begin{tabular}{llll}
\hline Gap \% men/women in $\mathrm{p}>0.62017$ & & \\
\hline ISCO & Sector & Italy & Chile \\
\hline 9 & IIIa & 14.9 & $5.5 \%$ \\
9 & IIIb & 11.7 & $12.4^{\mathrm{a}}$ \\
9 & IIIc & 10.8 & $11.6^{\mathrm{a}}$ \\
9 & IIId & 6.6 & $6.6^{\mathrm{a}}$ \\
\hline
\end{tabular}

${ }^{a}$ Subsamples with size less than 50 cases

\section{References}

Boll C., Rossen A., \& Wolf A. (2017). The EU gender earnings gap: Job segregation and working time as driving factors. Journal of Economics and Statistics, pp 407-452.

Charles, M., \& Grusky, D. (2004). Occupational ghettos: The worldwide segregation of women and men. Stanford, CA: Stanford University Press.

Charles, M., \& Grusky, D. (2011). Egalitarianism and gender inequality. In The inequality reader: Contemporary and foundational readings in race, class, and gender (pp. 327-342). Boulder, CO: Westview Press.

Cherry, M. A., \& Aloisi, A. (2016). Dependent contractors in the gig economy: A comparative approach. American University Law Review, 66, 635.

Crompton, R. (Ed.) (2009). Restructuring gender relations and employment: The decline of the male breadwinner model (p. 201). Oxford: Oxford University Press.

De Oliveira, O., \& Ariza, M. (1999). Trabajo, familia y condición femenina: Una revisión de las principales perspectivas de análisis. Papeles de Población, 5(20), 89-127.

Doeringer, P., \& Piore, M. (1971). Internal labor markets and manpower analysis. Lexington, MA: Heath. https://doi.org/10.2307/2521766.

Duncan, O. D., \& Duncan, B. (1959). A methodological analysis of segregation indexes. American Sociological Review, 20, 210-217.

Edwards, R., Reich, M., \& Gordon, D. (Eds.). (1975). Labor market segmentation. Lexington, DC: Heath. https://doi.org/10.1177/003232927600600410.

Emerek, R., Figueiredo, H., González, P., Gonäs, L., \& Rubery, J. (2003). Indicators on gender segregation (p. 2). Porto: Rapport, CETE, Faculdade de Economia, Universidade do Porto.

Esping-Andersen, G., \& Billari, F. C. (2015). Re-theorizing family demographics. Population and Development Review, 41(1), 1-31.

Espino, A., \& De los Santos, D. (2019). La segregación horizontal de género en los mercados laborales de ocho países de América Latina: Implicancias para las desigualdades de género. Chile: OIT-PNUD.

Eurostat. (2008). NACE rev.2 statistical classification of economic activities in the European Community. Working paper, ISBN 978-92-79-04741-1. Retrieved from https://ec.europa.eu/eurostat/docum ents/3859598/5902521/KS-RA-07-015-EN.PDF/dd5443f5-b886-40e4-920d-9df03590ff91?versi on $=1.0$.

Eurostat. (2009). Task Force on the Quality of the Labour Force Survey. Final Report. Retrieved from http:// ec.europa.eu/eurostat.

Grimshaw, D., Fagan, C., Hebson, G., \& Tavora, I. (2017). Making work more equal. Manchester, UK: Manchester University Press.

Grusky, D. B., \& Charles, M. (1998). The past, present, and future of sex segregation methodology. Demography, 35(4), 497-504.

Hakim, C. (2000). Work-Lifestyle Choices in the 21st Century. Oxford University Press.

Hoffman, S., \& Averett, S. (2016). Women and the economy. London: Palgrave.

ISTAT. (2013). La classificazione delle occupazioni. Roma: Istituto Nazionale di Statistica. https://www. istat.it/en/files/2013/07/la_classificazione_delle_professioni.pdf.

Karmel, T., \& MacLachlan, M. (1988). Occupational sex segregation-Increasing or decreasing? Economic Record, 64(3), 187-195.

Mead, M. (1949). Male and female: A study of the sexes in a changing world. New York: William Morrow. 
OECD. (2019). Labour force statistics in OECD countries: Sources, coverage and definitions. Retrieved February 7, 2020, from OECD website http://www.oecd.org/els/emp/LFS\%20Definitions\%20-\%20Tab les.pdf.

Orellana, V. (2011). Nuevos estudiantes y tendencias emergentes en la educación superior. Una mirada al Chile del mañana. Nueva geografía de la educación superior y de los estudiantes: Una cartografía del sistema chileno, su actual alumnado y sus principales tendencias (pp. 80-142).

Pinto, A. (1976). Naturaleza e Implicaciones de la heterogeneidad estructural de América Latina. In El trimestre economico (Vol. 37(145)). Mexico DF: Fondo de Cultura Económica.

Rubery, J. (1978). Structured labour markets, worker organisation and low pay. Cambridge Journal of Economics, 2(1), 17-36. https://doi.org/10.1093/oxfordjournals.cje.a035375.

Ruiz, C. (2019). La política en el neoliberalismo: Experiencias latinoamericanas. Santiago de Chile: LOM Ediciones.

Ruiz, C., Boccardo, G. (2014). Los chilenos bajo el neoliberalismo. Clases y conflicto social. Santiago: El Desconcierto.

Salvia, A., \& Chavez Molina, E. (2013). Sombras de una marginalidad fragmentada. Buenos Aires: Mino y Davila.

Semenza, R., \& Sarti, S. (2019). Labour market segmentation: the economic condition of independent professionals in Italy and Argentina. Papers: revista de sociologia, 104(2), 0203-0223. https://doi. org/10.5565/rev/papers.2578.

Siltanen, J., Jarman, J., \& Blackburn, R. M. (1995). Gender inequality in the labour market: Occupational concentration and segregation. Geneva: International Labour Organization.

Vosko, L., MacDonald, M. \& Campbell, I. (2009). Gender and the Contours of Precarious Employment. London: Routledge.

Wooldridge, J. M. (2010). Econometric analysis of cross section and panel data. Cambridge, MA: MIT Press.

Publisher's Note Springer Nature remains neutral with regard to jurisdictional claims in published maps and institutional affiliations. 